الكفايـات التدريسية اللازمـة لمعلمي التربيـة الرياضـية بمعاهــ ومـدارس التربيـة الفكريـة بالمملكـة العربية السعودية. هشام عبداله محمد الربيع معلم - الادارة العامة للتعليم - وزارة التعليم - المملكة العربية السعودية.

المقدمة ومثكلة البحث

تعد التربية من أهم الأدو ات التي تعتمدها المجتمعات باختلاف أنماطها في التخطبط والتطوير لبر امج التنميـة الثـاملة ..

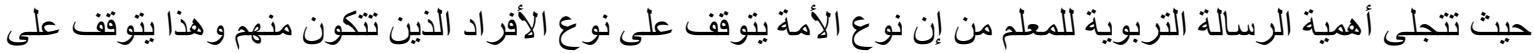

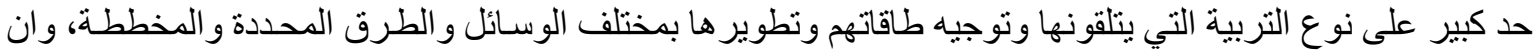
أهم العو امل في نقرير نوع التربية هو نوع التوبة المعلمين.

ويعد المعلم أهم مدخلات العملية التعليمية و أخطر ها بعد الطلبة، و الإسلام يبين أهمية المعلم ومـا لهذه المهنـة مـن مكانـة

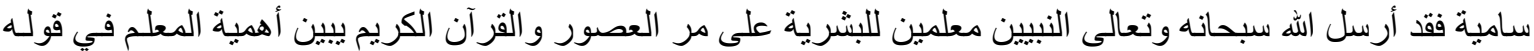

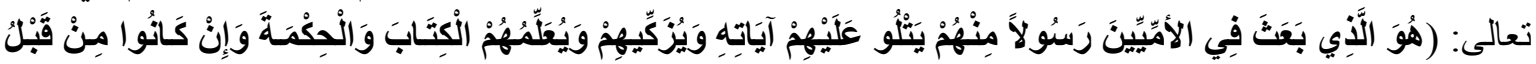

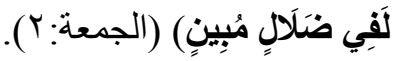

وقد وصف التربويون المعلم بصفات كثبرة ودللوا على دوره المهم باعتبار ات مهمة توضح مكانته في العملية التربويـة

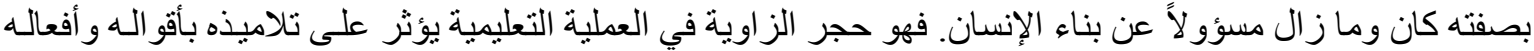
ومظهره وسائر تصرفاته التي ينقلها التلاميذ عنه بطريقة شعورية أو غير شعورية (ابر اهيم، 999 ( 99 : • ب). وتوجد اتجاهات حديثة أكدت عليها مبادئ التربية المعاصرة تؤكد على تحويل النظريـات و الأسس العلميـة إلى كفايات

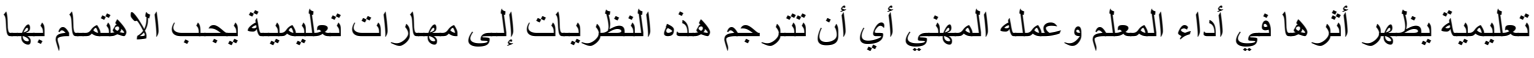

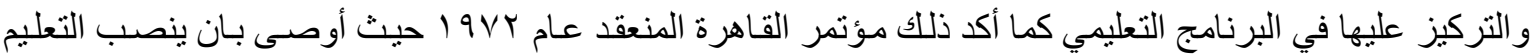

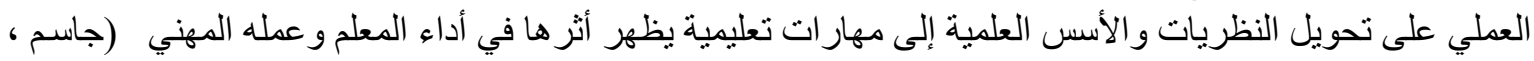
. (^) (1997

و هذا الاتجاه جاء كرد فعل للأساليب التقليدية لبر امج الإعداد لأنها تهمل الأداء و الدافع ممـا يؤدي إلى الانفصـال بين مـا

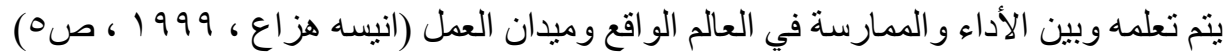
و ون هنا فان مدخل الكفايات يمكن أن يكون مناسباً للنهوض بهذه البر امج التدريسية العالية كاتجاه جديد لتربيـة المعلمين

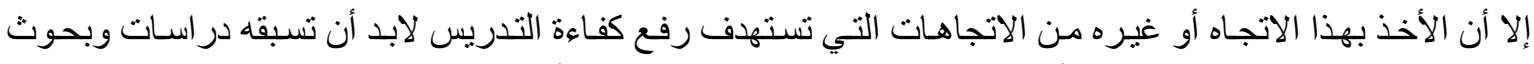

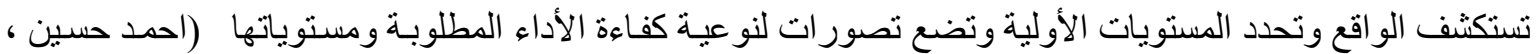

كما اكدت العديد من المؤتمرات في الدول العربيـة على أهمية اعداد المعلمين، ففي الإمـار ات العربية المتحدة عقدت

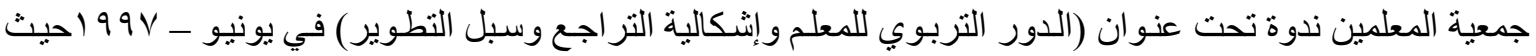

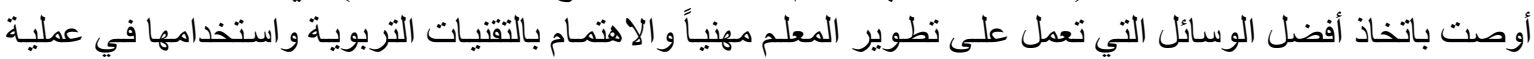

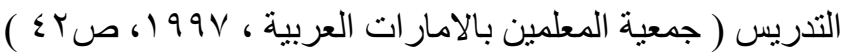

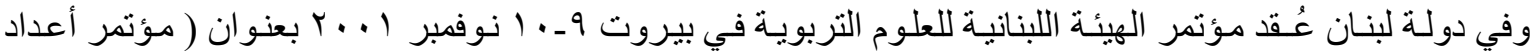
المعلمين في البلدان العربية ) فقد أوضح بأن أنظمة أعداد المعلمين على الرغم مما عرفته من تطور ات ماز الت مقصرة 
في تأمين المستوى المطلوب من المهار ات و المعارف و المو اقف ليقوم المعلمون بدور هم المهني على نحو جيد. (الهيئة

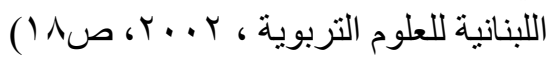
وتعتبر مشكلة الإعاقة الذهنية من أكثر المشكلات التي تشغل الفكر الإنساني باعتبار ها مشكلة اقتصادية واجتماعية ويعد

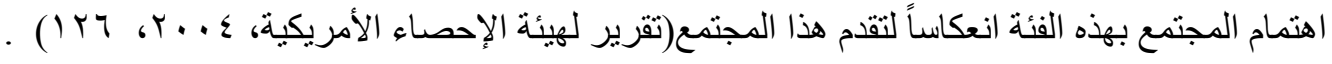
وقد كان المفهوم القديم للمعاقين ذهنياً أنهم أفر اد غير قابلين للتغيير أو التعديل وتلك النظرة أدت إلى إهـال تلك الفئة

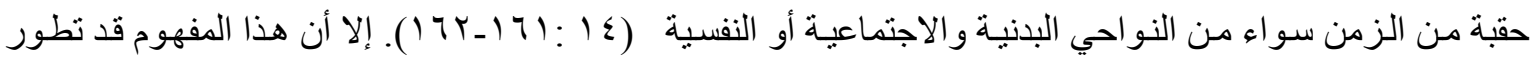

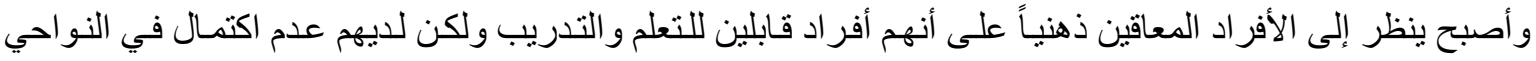

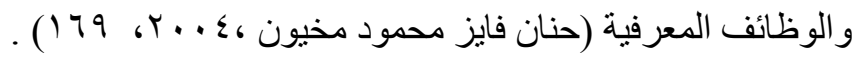

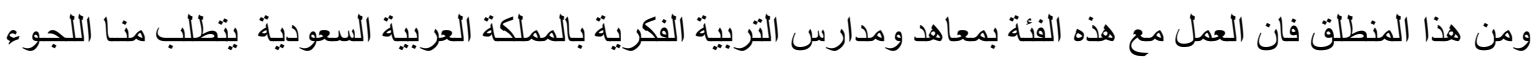

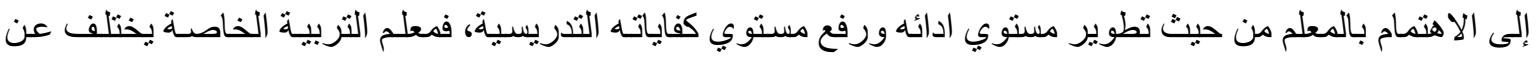

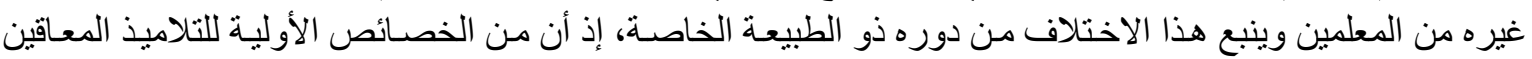

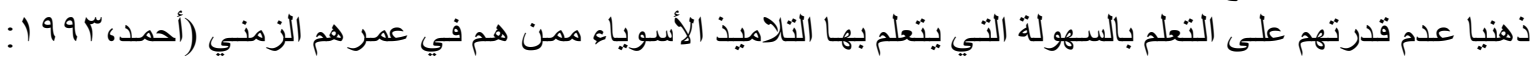

و الباحث في بحثه الحسالي يسعى الى تحديد اهم الكفايـات التدريسية اللازمـة لمعلمي المعاقين ذهنيا وذلك من خـلال

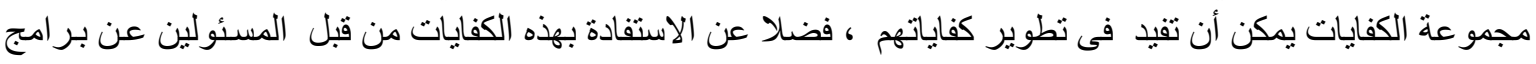
اعداد معلمي التربية الخاصة بالمملكة العربية السعودية وذللك ضمن بر امج الدونية الدور ات التدريية التي تعقد لتطوير معلمي التربية الخاصة. هدف البحث : يهدف البحث الحالي إلى التعرف على الكفايات التدريسية اللازمـة لمعلمي التربيـة الرياضية بمعاهد ومدارس التربيـة الفكرية بالمملكة العربية السعودية.

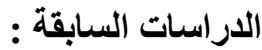

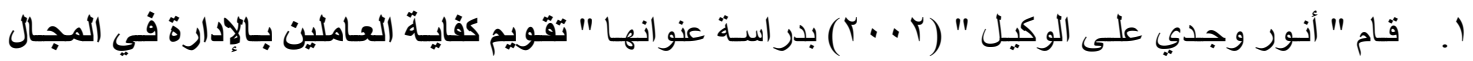

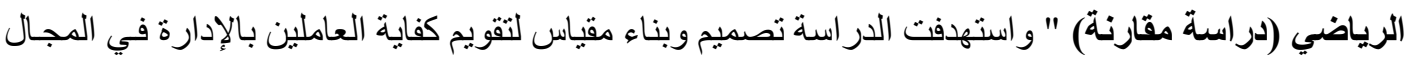

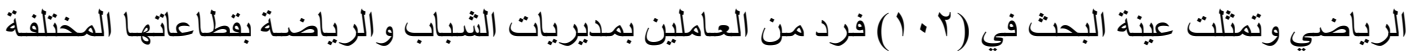

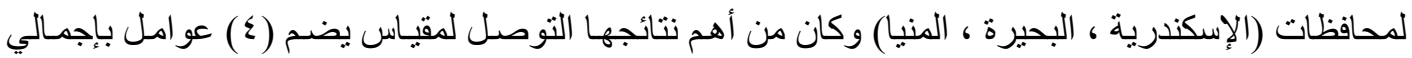

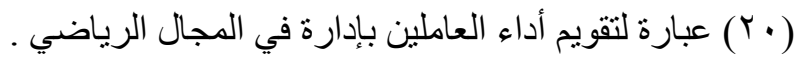

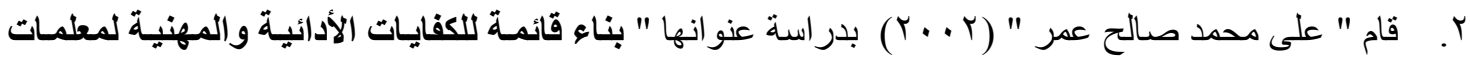

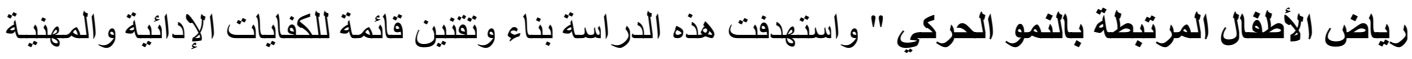

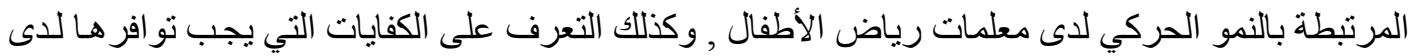

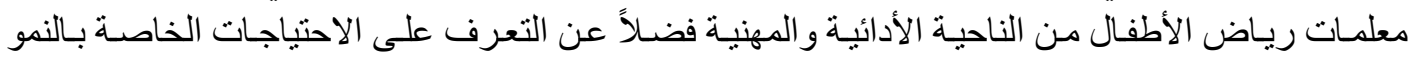

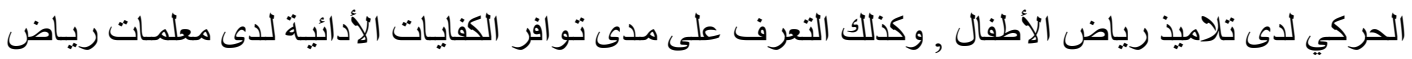

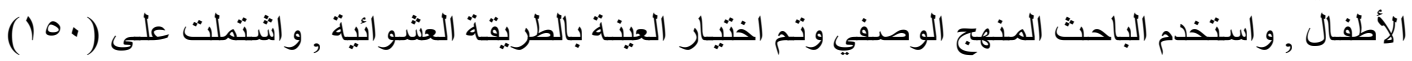

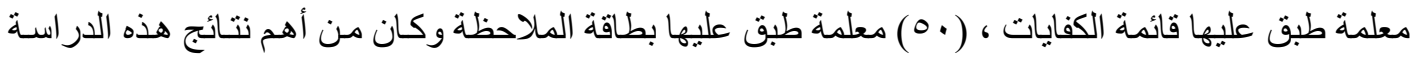

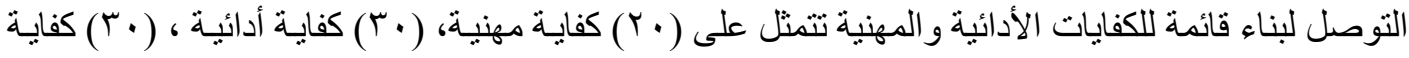
لملاحظة أداء المعلمات . لمائهة 


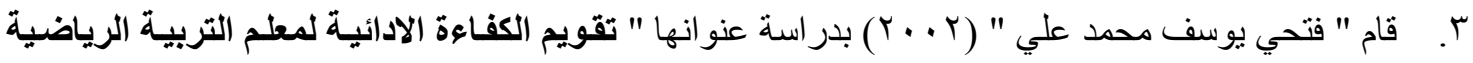

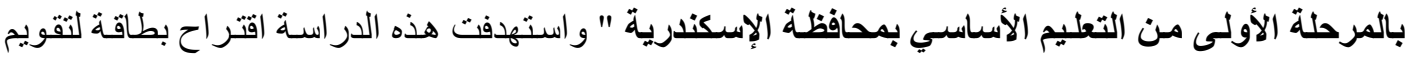

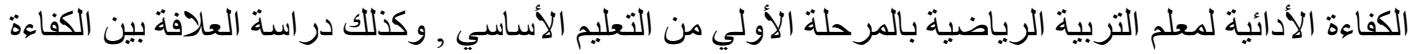

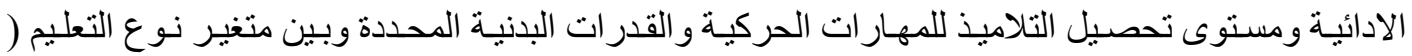

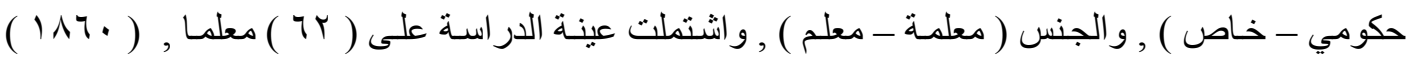

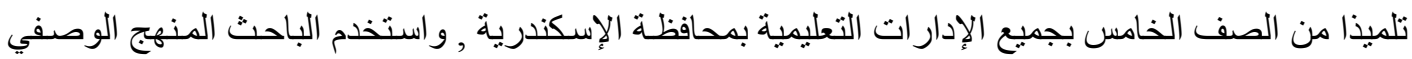

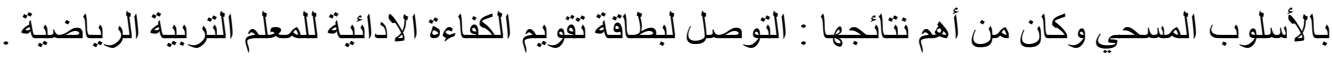

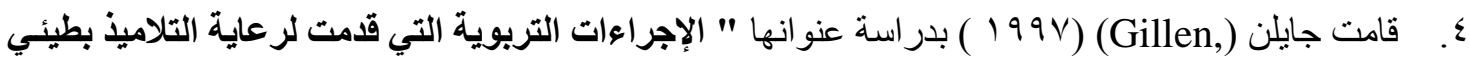

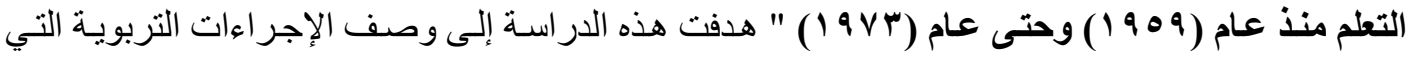

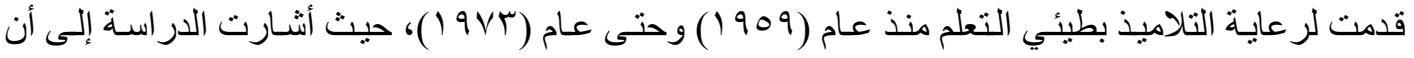

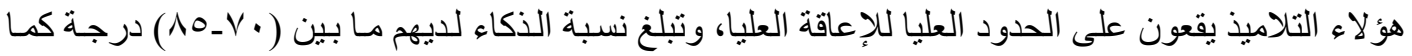

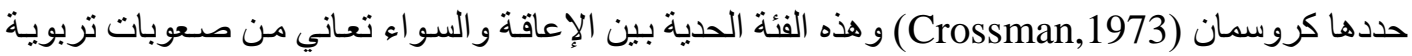

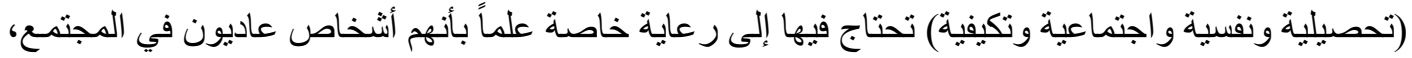

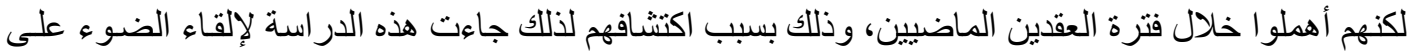
التطبيقات التربويـة في الصفوف المتوسطة في المجتمـع الحضـري في مركز كونكتكون (Connecticut)

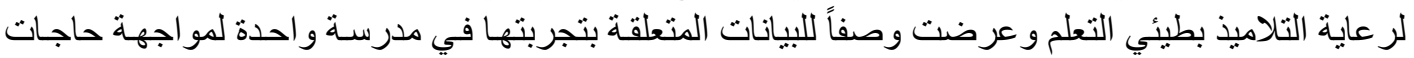

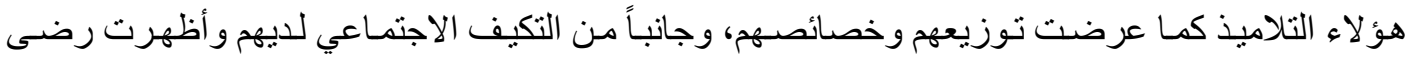

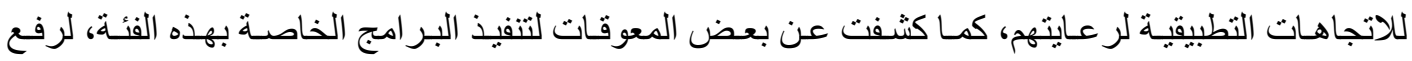

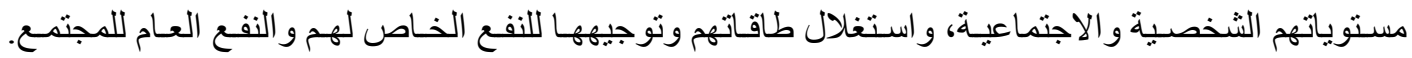

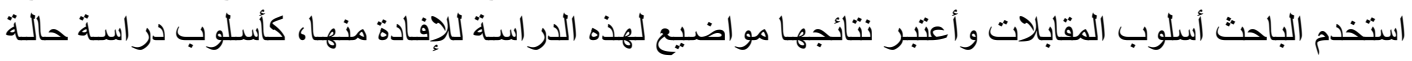

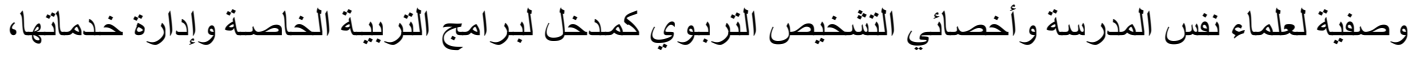

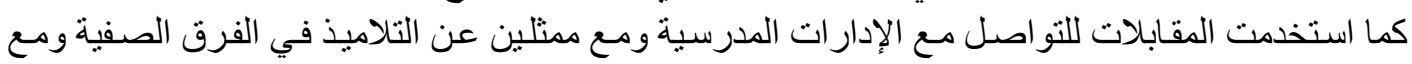

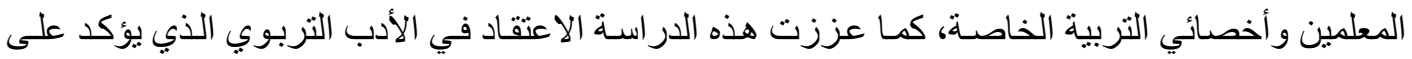
أهمية التشخيص المبكر في التربية الخاصة.

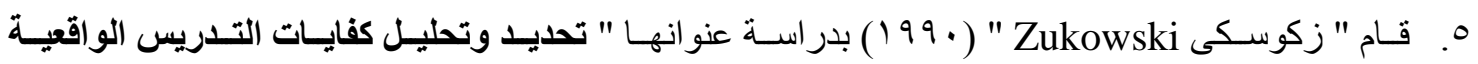

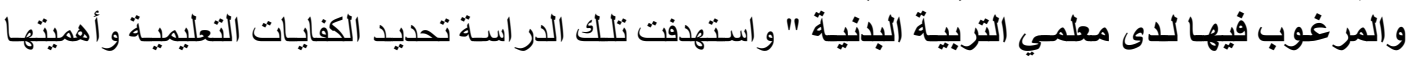

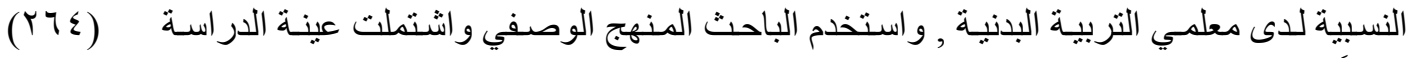

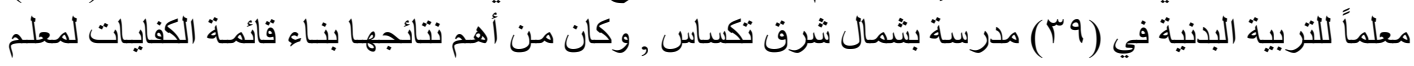

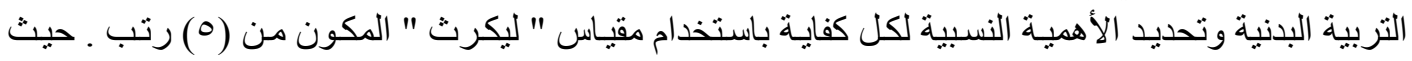

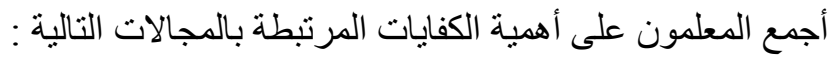

$$
\begin{aligned}
& \text { - تنظيم خطط الدروس اليومية . } \\
& \text { - } \\
& \text { - تكوين علاقات مع التلميذ }
\end{aligned}
$$

- توظيف العديد من طرق التدريس توظيفاً فعالاً . 
استخدم الباحث المنهج الوصفي (الدر اسات المسحية) لملاءمته لتحقيق هدف البحث .

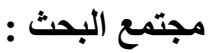

يتمتل مجتمع البحث الحالي فى معلمي التربيـة الرياضية بمدارس ذوي الاحتياجات الخاصـة بمدارس ومعاهد التربية الفكرية بالمملكة العربية السعودية .

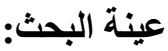

تم اختيار العينة بالطريقة العشو ائية من مجتمع البحث بالمملكة العربية السعودية وبلغ قو ام عينة البحث الاساسية (10 (ه ) معلم ، كما تم اختيار عدد (· r) معلما كعينة استطلاعية لإجر اء المعاء المعاملات العلمية للاستبيان .

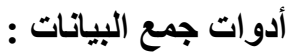

تم استخدام الاستبيان كأداة لجمع البيانات وذلك بإتباع الخطوات التالية :

قام الباحث بتحليل المتاح من المراجع و الدراسات العلمية المتخصصة فى مجال الكفايات ومجال الاعاقة الذهنية بهدف

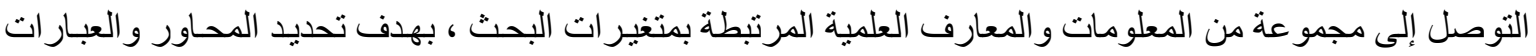

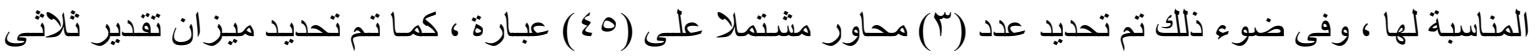

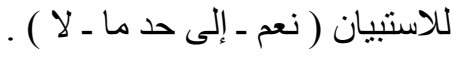

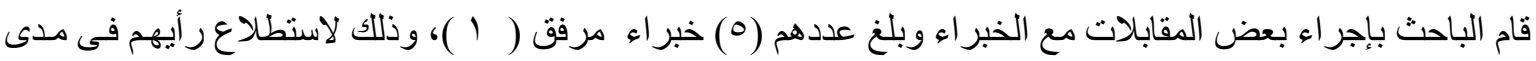

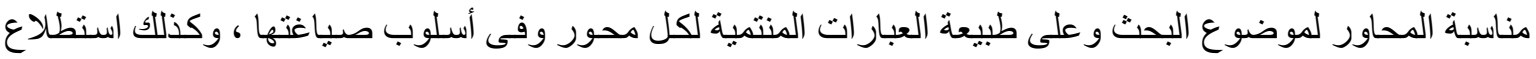
رأيهم فى تحديد ميزان التقدير المناسب للاستمارة .

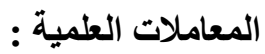

قام الباحث بأجر اء صدق وثبات الاستبيان بالطرق العلمية التالية :

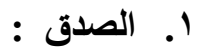

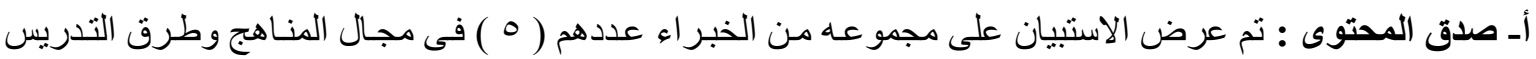

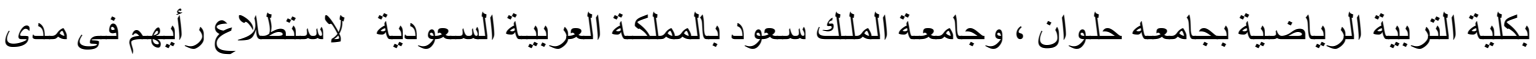

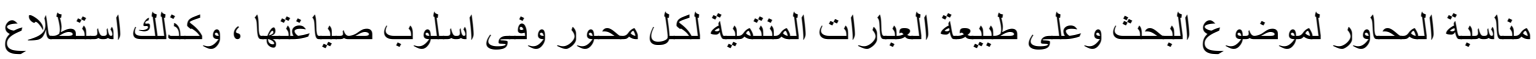

رايهم فى تحديد ميزان التقدير المناسب للاستمارة ملحق (1) (1) .

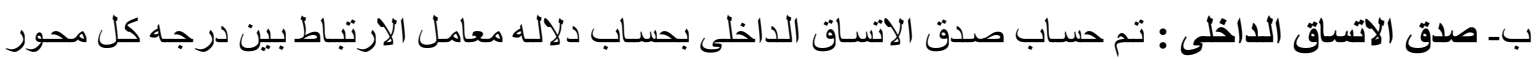

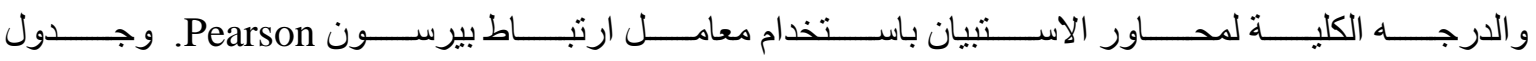
( ) يوضح ذلك. 


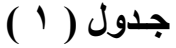

معامل الارتباط بين درجه كل محور والدرجة الكلية لمحاور الاستبيان (ن= •r)

\begin{tabular}{|c|c|c|}
\hline قيمة الارتباط* & عدد العبارات & مسمى المحور \\
\hline$\cdot, \wedge$ Y & IV & المحور الاول : التخطيط للارس \\
\hline$\cdot, \wedge 91$ & 11 & المحور الثاني : تنفيذ الدرس \\
\hline$\cdot, \vee \vee \neg \wedge$ & 1. & المحور الثالث : تقويم الدرس \\
\hline
\end{tabular}

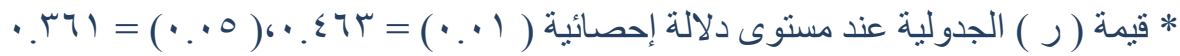

يتضح من جدول ( ا ) أن قيمة الارتباط بين درجة كل محور ومجموع الدرجة الكليـة لمحاور الاستبيان دالة إحصـائيا

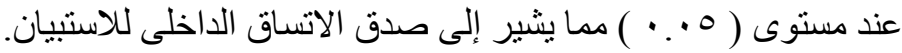

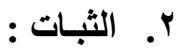

قام الباحث بتعيين الثبات باستخدام التجزئة النصفية عن طريق "معامل ألفا Alpha " للثبات وفقاً للمعادلة الإحصـائية

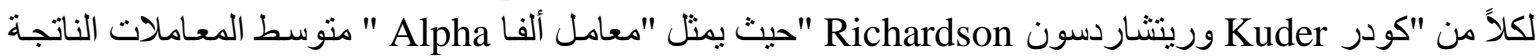

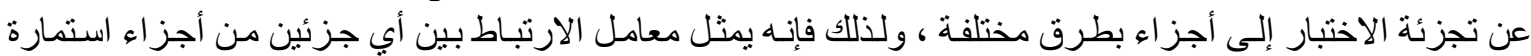
الاستبيان ويوضح جدول ( r ) معامل الثبات بطريقة ألفا.

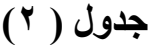

قيم معامل ألفا Alpha لمحاور استمارة الاستبيان (ن= (Y (Y)

\begin{tabular}{|c|c|c|}
\hline قيم معامل ألفا & عنوان المحور & المحور \\
\hline$\because \wedge \wedge r$ & التخطيط للارس & الأول \\
\hline$\cdot \wedge \leqslant \varepsilon$ & تتفيذ الدرس & الثاني \\
\hline$\because$ Aro & تقويم الارس & الثالث \\
\hline
\end{tabular}

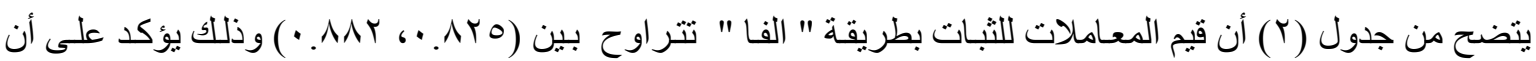

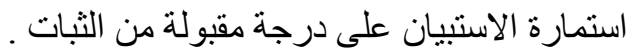

\section{خطوات تتفيذ البحث:}

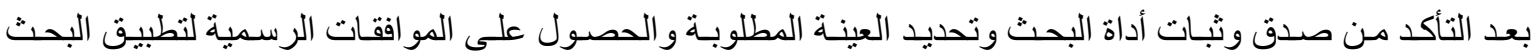

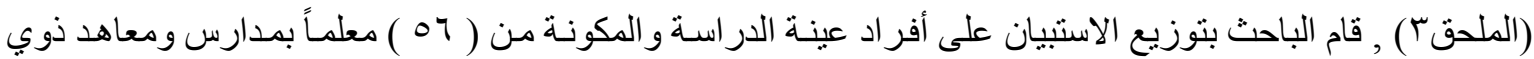

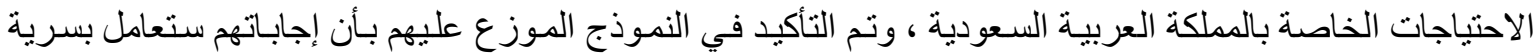

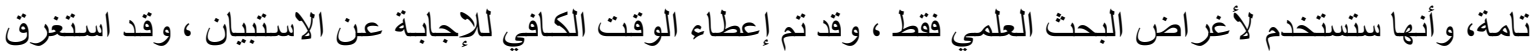

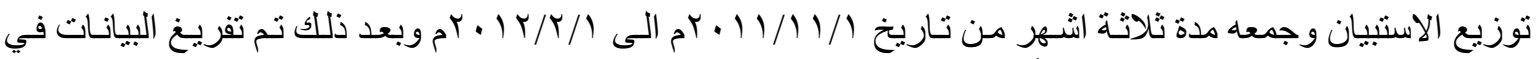
نموذج خاص بالحاسوب SPSS تمهيداً للمعالجة الإحصائية .

المعالجة الإحصائية:

لتحقيق هدف الدر اسة تم استخدام المعالجة الإحصائية الآتية : - - التكرارات و النسب المئوية .

- معامل ارتباط بيرسون للتأكد من صدق وثبات أداة البحث . 


\section{جدول (r)}

التكرارات والنسب المئوية لعبارات المحور الاول " التخطيط للارس (

\begin{tabular}{|c|c|c|c|c|c|c|}
\hline$\%$ & المجموع & ע & 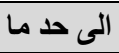 & نعم & 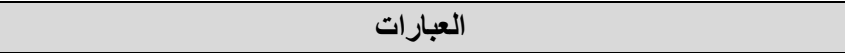 & p \\
\hline & & & & & أرى أن الكفايات التدريسية المرتبطة بححور تخطيط الدرس هي القدرة على & \\
\hline 85.7 & 144 & 4 & 16 & 36 & الإلمام بجميع الأنشطة التى يحويها منهاج التربية البدنية لذوي الاعاقة الذهنية & 1 \\
\hline 82.1 & 138 & 6 & 18 & 32 & الإلمام بكافة الإمكانات المادية المتاحة بالمدرسة & r \\
\hline 88.1 & 148 & 3 & 14 & 39 & معرفة المعوقات التي تحول دون تتفيذ الدرس بكفاءة & r \\
\hline 95.2 & 160 & 0 & 8 & 48 & فهم الحاجات النفسية و العقلية و الاجتماعية للمعاقين ذهنياً & $\varepsilon$ \\
\hline 86.9 & 146 & 7 & 8 & 41 & كتابة هدف الدرس بطريقة إجر ائية ( سلوكية ) & 0 \\
\hline 92.3 & 155 & 1 & 11 & 44 & تحقيق أهداف الوحدات التعليمية وفقا لأولويات تحقيقها & 7 \\
\hline 91.7 & 154 & 0 & 14 & 42 & توفير أنشطة بديلة إلي جانب الأنشطة التي يحويها منهج المعاقين ذهنياً & $\mathrm{v}$ \\
\hline 95.2 & 160 & 0 & 8 & 48 & اختيار ألانشطة التي تحقق الهذف من الدرس & $\wedge$ \\
\hline 92.9 & 156 & 0 & 12 & 44 & اختيار ألانشطة في ضوء الإمكانات المادية المتاحة بالمدرسة & 9 \\
\hline 100.0 & 168 & 0 & 0 & 56 & تحديد وسائل الآمان و السلامة الو اجب اتباعها خلال الدرس & 1. \\
\hline 96.4 & 162 & 0 & 6 & 50 & تحديد وسائل القياس المناسبة لمعرفة (المستوِى الحقيقي - مدي التقام ) للطفل & 11 \\
\hline 97.0 & 163 & 0 & 5 & 51 & 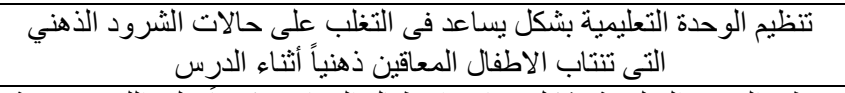 & IT \\
\hline 97.6 & 164 & 0 & 4 & 52 & 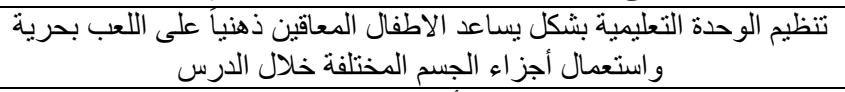 & ז \\
\hline 95.2 & 160 & 1 & 6 & 49 & 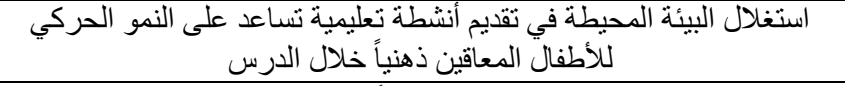 & $1 \leq$ \\
\hline 97.0 & 163 & 0 & 5 & 51 & إثباع حاجة الاطفال المعاقين ذهنياً إلى النشاط خلال الدرس & 10 \\
\hline 93.5 & 157 & 0 & 11 & 45 & تقديم أنشطة تعليمية تر اعي فيهاً استخدام الحواس المتعددة للأطفال المعاقين & 17 \\
\hline 98.8 & 166 & 0 & 2 & 54 & استخدام ألعاب تتلاعم مع مستوي النمو البدني & iv \\
\hline
\end{tabular}

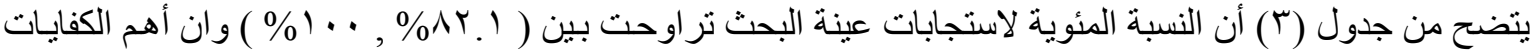

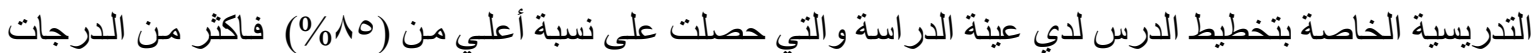

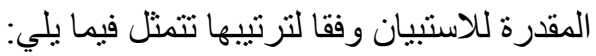
- تحديد وسائل الآمان و السلامة الو اجب اتباعها خلال الدرس. - استخدام ألعاب تتتلاءم مع مستوي النمو البدني .

ـ تنظيم الوحدة التعليمية بشكل يساعد الاطفال المعاقين ذهنياً على اللعب بحرية واستعمال أجز اء الجسم المختلفة خلال الدرس.

- ـ ت تنظيم الوحدة التعليمبة بشكل بساعد فى التغلب على حالات الثرود الذهني التى تنتاب الاطفال المعاقين ذهنياً أنثاء الدرس. - إثباع حاجة الاطفال المعاقين ذهنياً إلى النشاط خلال الدرس. - - تحديد وسائل القياس المناسبة لمعرفة (المستوى الحقيقي ـ مدي التقدم ) للطفل المعاق ذهنياً. ـ استغلال البيئة المحيطة في تقديم أنشطة تعليميـة تسـاعد على النمو الحركي للأطفـال المعـاقين ذهنياً خـلال الدرس. 
-

- - فهم الحاجات النفية و العقلية و الاجتماعية للمعاقين ذهنياً. - - تقديم أنشطة تعليمية تر اعي فيها استخدام الحواس المتعددة للأطفال المعاقين ذهنياً خلال الدرس. - اختيار ألانشطة في ضوء الإمكانات المادية المتاحة بالمدرسة.

- تحقيق أهداف الوحدات التعليمية وفقا لأولويات تحقيقها. - توفير أنشطة بديلة إلي جانب الأنشطة التي يحويها منهج المعاقين ذهنياً. - معرفة المعوقات التي تحول دون تتفيذ الدرس بكفاءة. - الإلمام بجميع الأنثطة التى يحويها منهاج التربية البدنية لذوي الاعباقة الذهنية.

$$
\begin{aligned}
& \text { - كتابة هدف الدرس بطريقة إجر ائية ( سلوكية ). } \\
& \text { ويرى الباحث أن ذلك يرجع إلى : }
\end{aligned}
$$

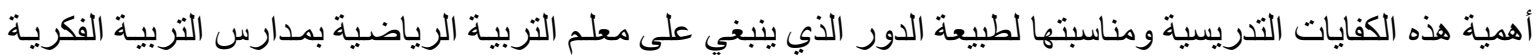

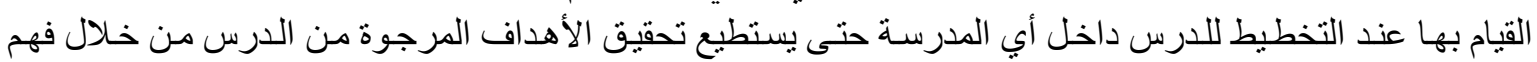

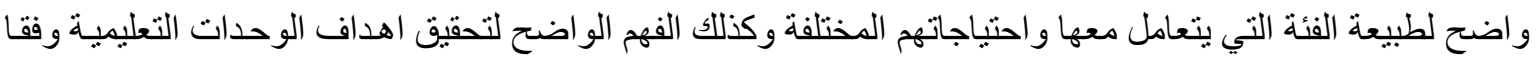

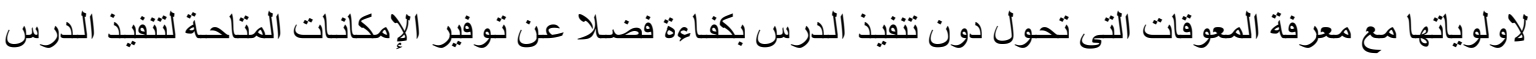

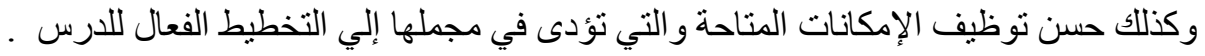

\section{و هذه النتائج تتفق مع آراء كل من : ع}

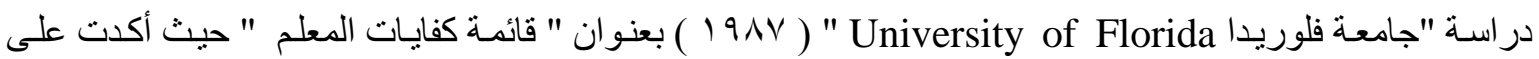

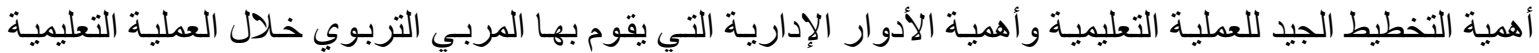

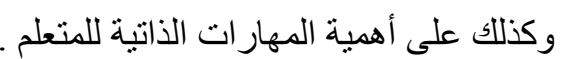

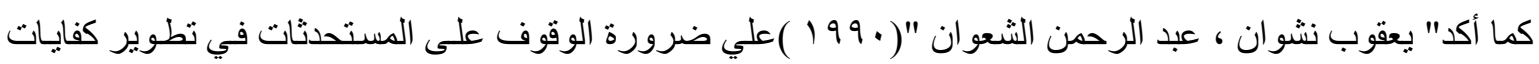

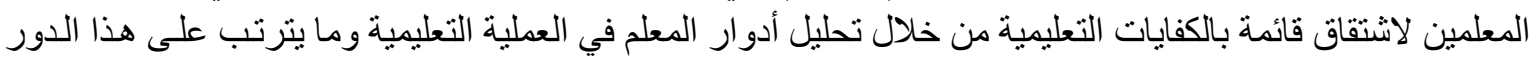

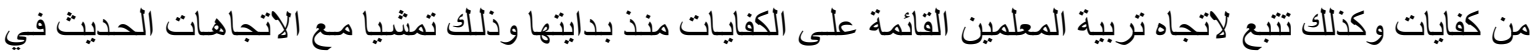
التربية.

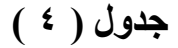

\begin{tabular}{|c|c|c|c|c|c|c|}
\hline$\%$ & 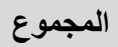 & V & 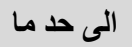 & نعم & 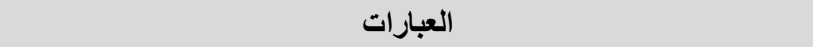 & م \\
\hline & & & & & أرى أن الكفايات التدريسية المرتبطة بمحور تنفيذ الدرس هي القرة على & \\
\hline 99.4 & 167 & 0 & 1 & 55 & 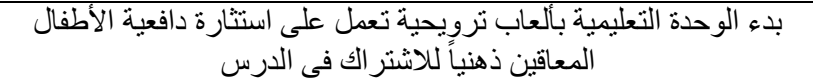 & 1 \\
\hline 95.8 & 161 & 0 & 7 & 49 & تقديم الأنشطة التعليمية للأطفال المعاقين ذهنياً بطريقة سهلة وشيقة & $r$ \\
\hline 100.0 & 168 & 0 & 0 & 56 & تقديم الأنشطة التعليمية بطريقة تناسب ذهنياًجات وخصائص النمو للاظطفال & $r$ \\
\hline 98.8 & 166 & 0 & 2 & 54 & 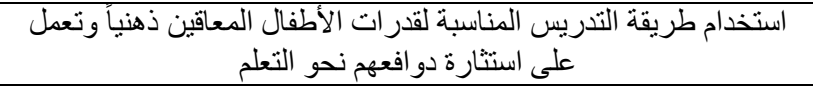 & $\varepsilon$ \\
\hline
\end{tabular}

التكرارات والنسب المئوية لعبارات المحور الثاني " تنفيذ للارس " 


\begin{tabular}{|c|c|c|c|c|c|c|}
\hline$\%$ & 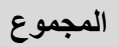 & ע & 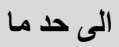 & 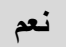 & 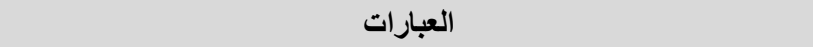 & b \\
\hline 98.8 & 166 & 0 & 2 & 54 & يشجع الأطفال المعاقين ذهنياً باستمر ار عند الأداء الجيد & 0 \\
\hline 96.4 & 162 & 0 & 6 & 50 & يعمل على تحقيق التفاعل الايجابي مع الأطفال المعاقين ذهنياً خلال الدرس & 1 \\
\hline 94.6 & 159 & 1 & 7 & 48 & يستطيع حل مشكلات التعلم لدى الأطفال المعاقين ذهنياً و التي قد تظهر & V \\
\hline 93.5 & 157 & 0 & 11 & 45 & يهتم بالجانب النفسي للأطفال المعاقين ذهنياً خلال الدرس & $\wedge$ \\
\hline 94.6 & 159 & 1 & 7 & 48 & توجيه التعليمات للاطفال المعاقين ذهنياً خلال الدرس بشكل تربوي & 9 \\
\hline 100.0 & 168 & 0 & 0 & 56 & التدرج من السهل للصعب و فهاً لحدود قدر ات واستعدادات الأطفال المعاقين & 1. \\
\hline 98.8 & 166 & 0 & 2 & 54 & استخدام الأدو ات البديلة داخل الوحدات التعليمية لاستثارة دافعية الأطفال & 11 \\
\hline 97.6 & 164 & 0 & 4 & 52 & استخدام الوسائل المعينة خلال الدرس & IT \\
\hline 96.4 & 162 & 0 & 6 & 50 & التأكيد على استمر ار الممارسة الفاعلة للأطفال المعاقين ذهنياً خلال الدرس & 14 \\
\hline 95.2 & 160 & 0 & 8 & 48 & اختيار الوسيلة التعليمية المناسبة لتحقيق أهداف كل جزء من أجزاء الدرس & $1 \leq$ \\
\hline 97.0 & 163 & 0 & 5 & 51 & تجهيز الوسيلة التعليمية قبل مو عد الدرس بفترة كافية & 10 \\
\hline 97.6 & 164 & 0 & 4 & 52 & 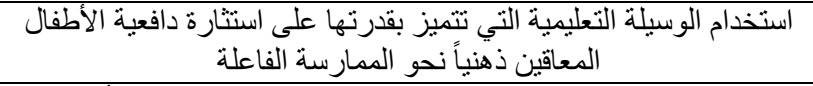 & 17 \\
\hline 97.0 & 163 & 0 & 5 & 51 & 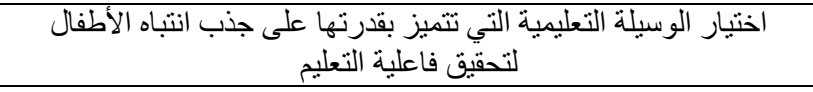 & IV \\
\hline 95.2 & 160 & 0 & 8 & 48 & إنهاء الدرس بطريقة شيقة وجذابة & 11 \\
\hline
\end{tabular}

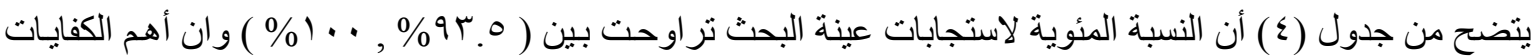

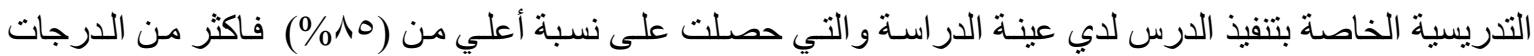
المقدرة للاستبيان وفقا لترتيبها تتمثل فيما يلي:

- التدرج من السهل للصعب وفقاً لحدود قدر ات و استعدادات الأطفال المعاقين ذهنياً خلال الدرس.

- - تقديم الأنشطة التعليمية بطريقة تتاسب احتباجات وخصائص النمو للأطفال المعاقين ذهنياً.

- بدء الوحدة التعليمية بألعاب ترويحية تعمل على استثارة دافعية الأطفال المعاقين ذهنياً للاشتر الك فى الدرس. - استخدام طريقة التدريس المناسبة لقدرات الأطفال المعاقين ذهنياً وتعمل على استنارة دو افعهم نحو التعلم. - - يشجع الأطفال المعاقين ذهنياً باستمر ار عند الأداء الجيد. ـ استخدام الوسيلة التعليميـة التي تتميز بقدرتها على استثنارة دافعيـة الأطفـال المعـاقين ذهنيـاً نحو الممارسـة الفاعلة. - تجهيز الوسيلة التعليمية قبل مو عد الدرس بفترة كافية. - اختيار الوسيلة التعليمية التي تتميز بقدرتها على جذب انتباه الأطفال لتحقيق فاعلية التعليم. - التأكيد على استمر ار الممارسة الفاعلة للأطفال المعاقين ذهنياً خلال الدرس. - - يعمل على تحقيق التفاعل الايجابي مع الأطفال المعاقين ذهنياً خلال الدرس. - - تقديم الأنشطة التعليمية للأطفال المعاقين ذهنياً بطريقة سهلة وشيقة. - - - 
- اختيار الوسبلة التعليمية المناسبة لتحقيق أهداف كل جزء من أجز اء الدرس.

- توجيه التعليمات للأطفال المعاقين ذهنياً خلال الدرس بشكل تربوي. - - يعمل على تحقيق التفاعل الايجابي مع الأطفال المعاقين ذهنياً خلال الدرس. - - يهتم بالجانب النفسي للأطفال المعاقين ذهنياً خلال الدرس.

ويرى الباحث أن ذلك يرجع إلى :

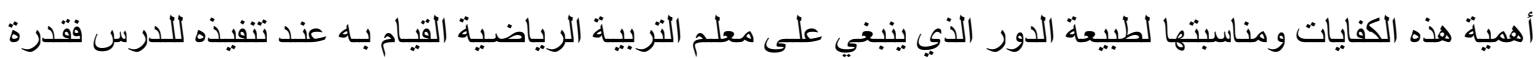

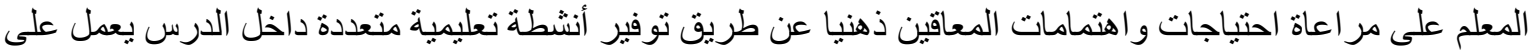

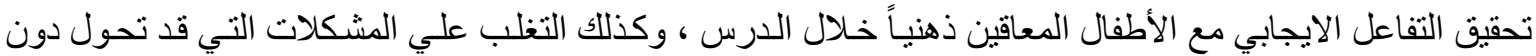

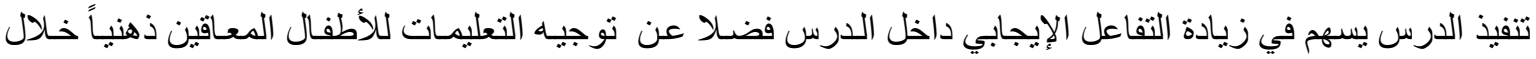

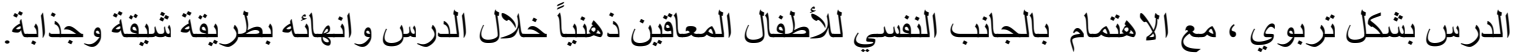

\section{و هذه النتائج تتثق مع آراء كل من :}

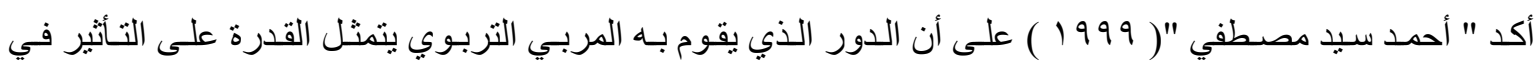
الآخرين من خلال الاتصال ليسعو ا بحماس و التزام إلى أداء مثمر يحقق أهدافاً مخططة.

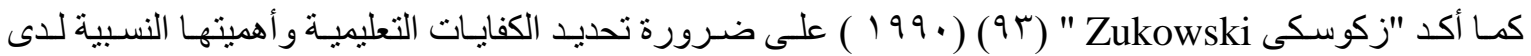

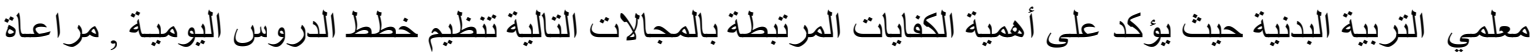

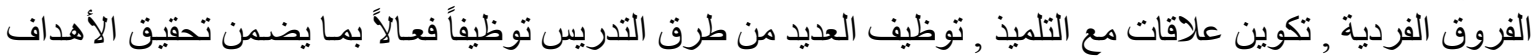

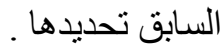

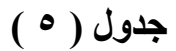

التكرارات والنسب المئوية لعبارات المحور الثالث " تقويم للارس "

\begin{tabular}{|c|c|c|c|c|c|c|}
\hline$\%$ & 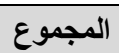 & ע & الى حـ ما & 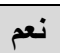 & 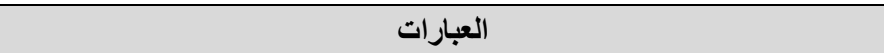 & م \\
\hline & & & & & أرى أن الكفايات التدريسية المرتبطة بمحور تقويم الدرس هي القدرة على & \\
\hline 100.0 & 168 & 0 & 0 & 56 & استخدام وسائل التقويم المناسبة لمعرفة مدي ما تحقق من أهداف المنهج & 1 \\
\hline 97.0 & 163 & 0 & 5 & 51 & استخدام وسائل تقويم علمية & r \\
\hline 96.4 & 162 & 0 & 6 & 50 & التأكد من أن الانشطة داخل الوحدة التعليمية تسهم في تحقيق احتباجات الاطفال & $r$ \\
\hline 97.6 & 164 & 0 & 4 & 52 & 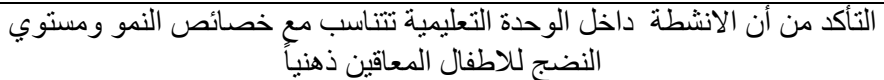 & $\varepsilon$ \\
\hline 96.4 & 162 & 0 & 6 & 50 & قياس مدى تحسن مستوي اللياقة البدنية للاطفال المعاقين ذهنباً & 0 \\
\hline 97.0 & 163 & 0 & 5 & 51 & قياس مستوى تحسن المهار ات الحركية للاطفال المعاقين ذهنياً & 7 \\
\hline 95.2 & 160 & 0 & 8 & 48 & قباس مستوى تحسن الحالة الصحية للاطفال المعاقين ذهنياً & V \\
\hline 100.0 & 168 & 0 & 0 & 56 & التحقق من أن الأنشطة داخل الوحدة التعليمية تحظى بالممارسة الفعالة من قبل & $\wedge$ \\
\hline 100.0 & 168 & 0 & 0 & 56 & التأكد من أن الأنشطة البديلة تسهم في تفعيل الدرس وتعمل على تحقيق أهدافه & 9 \\
\hline 100.0 & 168 & 0 & 0 & 56 & الاستفادة من عملية التقويم عند التخطيط للوحدات التعليمية الجديدة & 1. \\
\hline
\end{tabular}

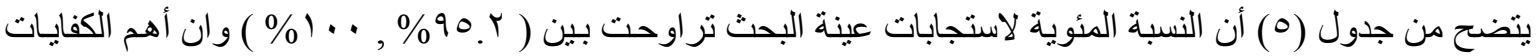

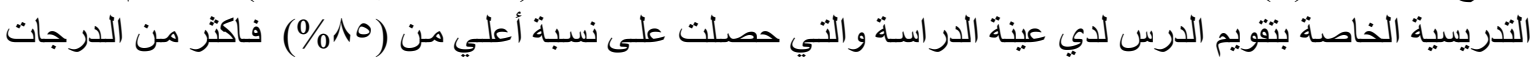
المقدرة للاستبيان وفقا لترتيبها تتمثل فيما يلي: 
- استخدام وسائل التقويم المناسبة لمعرفة مدي ما تحقق من أهداف المنهج.

- التحقق من أن الأنشطة داخل الوحدة التعليمية تحظى بالممارسة الفعالة من قبل الاطفال المعاقين ذهنياً. - التأكد من أن الأنثطة البديلة تسهم في تفعيل الدرس وتعمل على تحقيق أهدافه.

- الاستفادة من عملية التقويم عند التخطيط للوحدات التعليمية الجديدة.

- التأكد من أن الانشطة داخل الوحدة النعليمية تنتاسب مع خصائص النمو ومستوي النضـج للاطفال المعاقين ذهنياً.

- - - - استخدام وسائل تقويم علمية.

- - قياس مستوى تحسن المهارات الحركية للاطفال المعاقين ذهنياً.

- قياس مدى تحسن مستوي اللياقة البذنية للاطفال المعاقين ذهنياً.

- التأكد من أن الانشطة داخل الوحدة التعليمية تسهم في تحقيق احتباجات الاطفال المعاقين ذهنياً.

- قياس مستوى تحسن الحالة الصحية للاطفال المعاقين ذهنياً.

ويرى الباحث أن ذلك يرجع إلى :

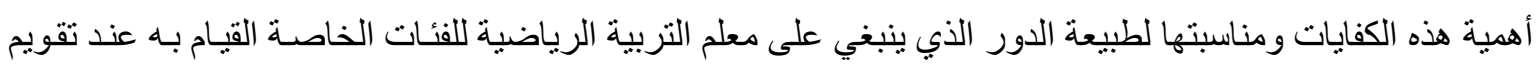

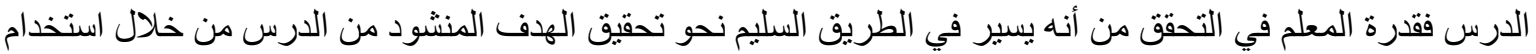

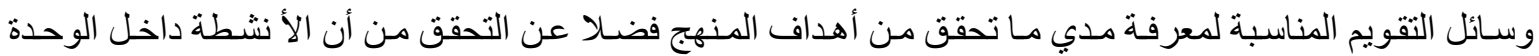

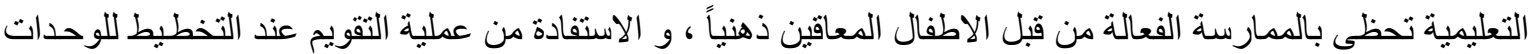

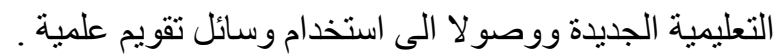

\section{وهذه النتائج تتنق مع آراء كل من :}

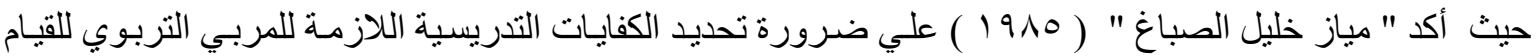

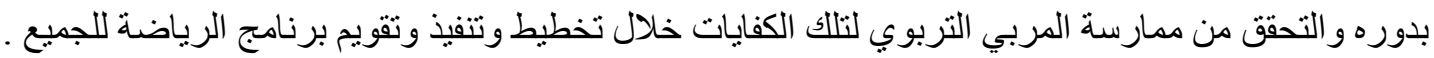

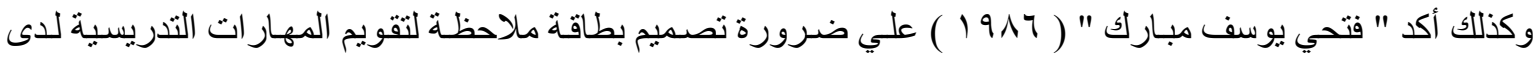
المربي التربوب و التي تؤثر على قدرته على القيام بعمله بكفاءة وفاعلية.

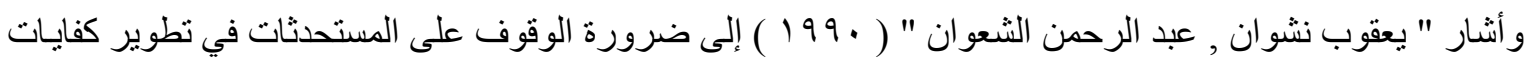

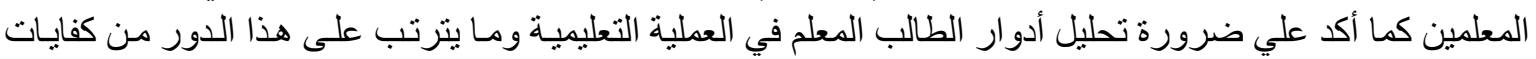
وكذلك تتبع لاتجاه تربية المعلمين القائمة على الكفايات منذ بدايتها لاشتقاق قائمة بالكفايات التعليمية .

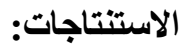

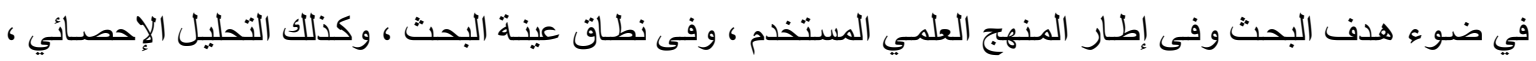

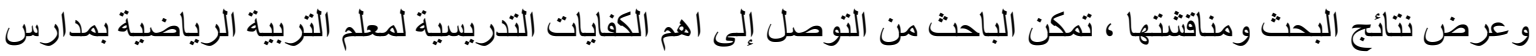

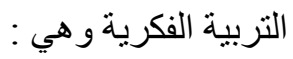

- الكفايات التدريسية الضرورية و اللازمة لمعلم التربية الرياضية بممدارس التربية الفكريـة مقسمة إلى ثلاثة

$$
\text { محاور انتملت على (0) ) مفردة و هي كآلاتي: }
$$

- المحور الأول " الكفايات التدريسية الخاصة بتخطيط الدرس" و اشتمل على (V ( ) مفردة. 
- المحور الثاني "الكفايات التدريسية الخاصة بتنفيذ الدرس" و اشتمل على (1) مفردة.

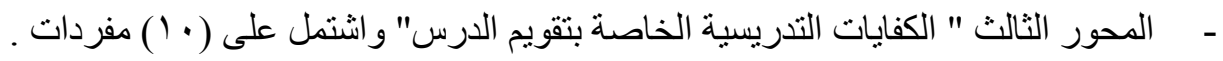

التوصيات : (1)

\section{في ضوء النتائج والاستنتاجات يوصى الباحث بالآتي:-}

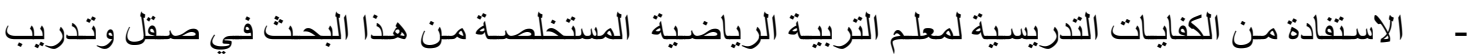

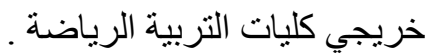

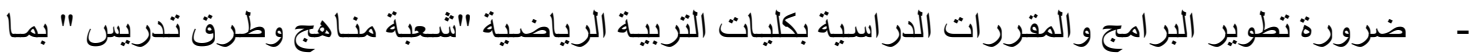

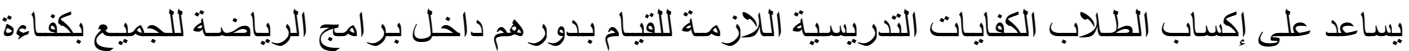
وفاعلية.

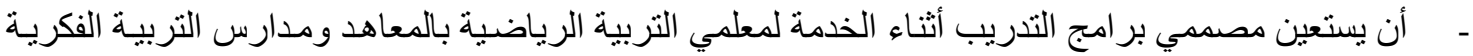
بالكفايات التنديسية المستخلصة من البحث في تحديد الكفايات اللازمة للمتدربين للقيام بأدو ارهم داخل التل الدرس.

المراجع: - إج

\section{أولاً :المراجع العربية:}

1. . إبر اهيم أحمد أحمد(999 1) : الإنشراف المدرسي و العيادي.القاهرة ، دار الفكر العربي، مصر. ؟. احمد حسين اللقاني ، ومحمد امين المفتي (r/91 ())، قائمة ملاحظة تقويم طلاب التربية العملية في كليات التربية ، كلية التربية ، جامعة عين شمس. r. احد سيد مصطفى ( 1999 ) : المدير في عالم متغير , دار قباء للنشر و التوزيع , القاهرة .

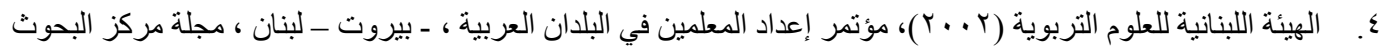

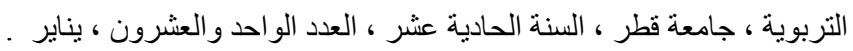

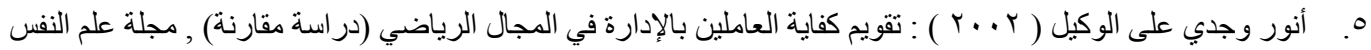

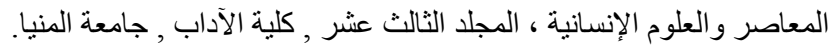
آ. انبسة هز اع (999 (19). الكفايات التعليمية اللازمة لمعلم اللغة العربية في المرحلة الثانوية في الجمهورية اليمنية ، جامعة صنعاء كلية التربية ، (رسالة ماجستير غير منشورة ) .

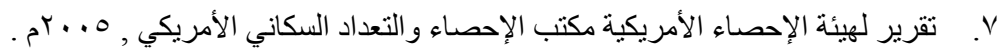
^. جمال الخطيب ، منى الحديدي (§991): مناهج وأساليب التدريس في التربية الخاصة ، مطبعة المعارف ، الثارقة ، الإمارات العربية المتحدة . 9. جمعية المعلمين الإمار ات العربية المتحدة (999 (1)، المعلم ، مجلة رسالة المعلم ، العدد VV ، الثارقة ، يونيو.

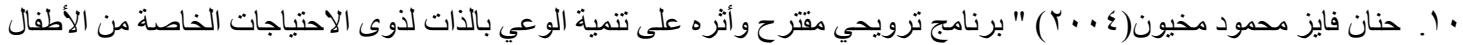

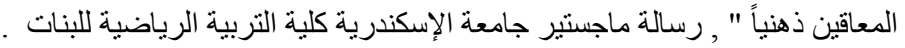
11. . على محمد صالح عمر ( r . . ) ) بناء قائمة الكفايات الأدائية والمهنية لمعلمات رياض الأطفال المرتبطة بالنمو الحركي ، رسالة ماجستير , غير منشورة ، كلية التربية الرياضية للبنين ، جامعة حلوان. 


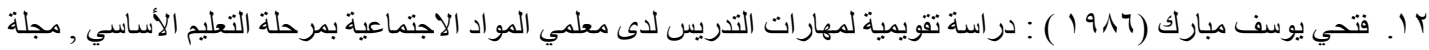

$$
\text { الأبحاث التربوية , العدد السادس , جامعة الأزهر . }
$$

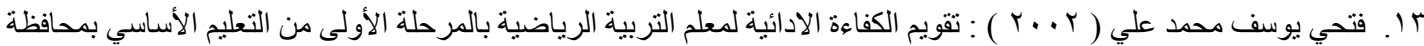
الإسكندرية , رسالة دكتور اه , غير منشورة , كلية التربية الرياضية للبنين , جامعة الإسكندرية .

ع ا. كلية التربية ، جامعة عين شمس (9AVV ( ) ): علم المرحلة الثانية ,وزارة التعليم العالي ، التقرير النهائي للبحث الذي قامت به كلية التربية بتكليف من وزارة التعليم العالي و البنك الدولي ، القاهرة.

10. مياز خليل الصباغ ( 1 (1 ) ) : تقويم مدرسات التاريخ بالمرحلة المتوسطة بالمملكة العربية السعودية في ضوء ما اكتسبنه من كفايات تدريسية , رسالة دكتور اه , غير منشورة , كلية التربية للبنات , الرياض .

7 ا. . نجاح فاضل جاسم( ج9 9 (1)، الكفايات التعليمية اللازمة لمعلمي التربية الأسلامبة في الحملة الأيمانية الوطنية الكبرى ، رسالة

$$
\text { ماجستير ، كلية التربية (ابن رشد) ، جامعة بغداد . }
$$

V ا . يعقوب نشوان , عبد الرحمن الشعوان ( • 99 ) ) : الكفايات التعليمية لطلبة كليات التربية بالمملكة العربية السعودية , مجلة جامعة الملك سعود للار اسات الإسلامية و العلوم التربوية , المجلد الثاني , الرياض ..

\section{ثانياً :المراجع الأجنبية:}

18. Gillen, Jean(1997). What happens slow learners Dersriptive dersriptiudy study of Educational practices Diss Abast, Vol.58, No.6,

19. Mary, Foly Mcienerney(1906). A comparison of computer Assisted Instruction with Teacher Managed Instructional practices, D.A.I., vol.55, No.7, Jan,. P.1907.

20. Zukowski, James Joun (1990) : "The Identification and Analysis of Actual and Desirable Teaching Competencies of Secondary school” Instructors of Academic subjects, Subjects, Dissertation Abstracts International, Vol. 40, N. 7, Jan. 
